\title{
Infectious and congenital syphilis in Canada, 2010-2015
}

\author{
Y Choudhri', J Miller' ${ }^{1}$, J Sandhu' ${ }^{1}$ A Leon ${ }^{1}$, J Aho ${ }^{1 *}$
}

\section{Abstract}

Background: Syphilis is the third most commonly reported notifiable sexually transmitted infection (STI) in Canada, following chlamydia and gonorrhea, respectively. Rates of this STI have been rising rapidly in Canada since 2001.

Objective: To summarize trends observed in syphilis rates for 2010 to 2015 in Canada.

Methods: Laboratory-confirmed cases of infectious syphilis and early congenital syphilis were reported to the Public Health Agency of Canada by all of the Canadian provinces and territories. National infectious syphilis rates were computed, as were rates per sex, age group and province/territory. Rates of congenital syphilis were also calculated.

Results: From 2010 to 2015, the rate of infectious syphilis in Canada increased by $85.6 \%$, from 5.0 to 9.3 cases per 100,000 population. In 2015, a total of 3,321 cases of infectious syphilis were reported, mainly in males (93.7\%), among whom the rate was 17.5 cases per 100,000 males versus 1.2 per 100,000 females. The rate also rose faster among males in 2010-2015, a 90.2\% increase versus $27.8 \%$ among females. Individuals aged $20-39$ years had the highest rates. Across the provinces and territories, the highest rates of infectious syphilis were in Nunavut, British Columbia and Manitoba.

The rate of congenital syphilis decreased from 2010 to 2014 (1.6 to 0.3 cases per 100,000 live births) before increasing to 1.5 cases per 100,000 live births in 2015 , which corresponds to six reported cases.

Conclusion: Rates of syphilis continue to rise in Canada, especially among young men, and this is consistent with trends in the United States of America and European Union. Based on data from Canada and from these regions, the sexual behaviour of men who have sex with men (MSM) is thought to be a major risk factor for syphilis.
Affiliation

${ }^{1}$ Centre for Communicable Diseases and Infection Control, Public Health Agency of Canada, Ottawa, ON

*Correspondence: josephine. aho@canada.ca

Suggested citation: Choudhri Y, Miller J, Sandhu J, Leon A, Aho J. Infectious and congenital syphilis in Canada, 2010-2015. Can Commun Dis Rep. 2018;44(2):43-8. https://doi.org/10.14745/ccdr.v44i02a02

\section{Introduction}

Syphilis, caused by the bacterium Treponema pallidum (1), is the third most commonly reported notifiable sexually transmitted infection (STI) in Canada, after chlamydia and gonorrhea, respectively. If left untreated, a primary syphilis infection can progress through secondary, latent and tertiary disease stages (2). Out of the four stages of syphilis, only three are infectious and therefore of public health significance: primary, secondary and early latent syphilis (1). Neurological symptoms can occur at any stage. Symptoms of infection in the earlier stages include chancres, condyloma lata and generalized lymphadenopathy. Cardiologic and musculoskeletal manifestations may occur if the infection remains untreated and reaches the tertiary stage. There is a synergy between HIV and syphilis as syphilis infection increases HIV viral load and HIV transmission (2). Moreover, for exposed individuals, HIV acquisition is two- to five-fold higher among those infected with syphilis than those without syphilis infection (2).
Congenital syphilis occurs through mother-to-child transmission, mainly in utero but also at birth. Congenital syphilis may have severe consequences for the newborn, such as cerebral palsy, hydrocephalus, sensorineural hearing loss, musculoskeletal deformity or death (3). The risk of transmission varies from $10 \%$ to more than $70 \%$ depending on the mother's stage of disease (3). Transmission may be prevented with timely diagnosis and adequate treatment.

After years of low incidence among both males and females, there has recently been a large increase in the number of syphilis cases, mainly among males (1). This rate increase coincides with the growing number of outbreaks reported in several cities and provinces across Canada among men who have sex with men (MSM), and especially among HIV-infected MSM, the heterosexual population and some Indigenous communities (1). 
The objective of this article is to summarize observed trends in reported laboratory-confirmed infectious syphilis and congenital syphilis rates in Canada in the period 2010 to 2015. Rates were analyzed by sex, age and geographic distribution.

\section{Methods}

\section{Data sources}

Provincial and territorial health authorities provide non-nominal data on laboratory-confirmed cases to the Public Health Agency of Canada (PHAC) through the Canadian Notifiable Disease Surveillance System (CNDSS) (4). Confirmed case definitions of infectious syphilis and congenital syphilis are presented in the Appendix (5).

Variables submitted along with the diagnosis include sex, age at time of diagnosis, year of diagnosis and province/territory of diagnosis. All stages are notifiable but only infectious stages (primary, secondary and early latent) were included in this report. The received data were validated in collaboration with the corresponding province or territory. Data from January 1, 2010 to December 31, 2015 were available from all provinces and territories and were extracted from the CNDSS in July 2017.

\section{Data analysis}

Descriptive analysis was performed using Microsoft Excel. National annual reported case rates of infectious syphilis were computed per 100,000 population (or per males or females) for all years using number of cases from the CNDSS as numerators, and Statistics Canada yearly population estimates as denominators. Sex, age group and province/territory-specific rates were also calculated. For congenital syphilis, rates were computed per 100,000 live births. For 2014 and 2015, preliminary numbers of live births drawn from Statistics Canada were used, as final numbers were not yet available. No statistical procedures were used for comparative analyses. Small numbers are more susceptible to change and so corresponding rates should be interpreted with caution. Previous reports may provide different rates for some years due to reporting delays and data updating.

\section{Results}

From 2010 to 2015, the rate of reported laboratory-confirmed cases of infectious syphilis in Canada increased from 5.0 to 9.3 cases per 100,000 population (Figure 1). This represents an increase of $85.6 \%$ over this time period.

\section{Sex and age}

In 2015 , a total of 3,321 cases of infectious syphilis were reported, of which $93.7 \%$ were males. This was reflected in the much higher rate of infectious syphilis among males than among females (17.5 cases per 100,000 males versus 1.2 cases per 100,000 females). The rate of infectious syphilis also increased faster among males than among females in 2010-2015 ( $90.2 \%$ among males versus $27.8 \%$ among females) (Figure 1 ).
Figure 1: Overalla and sex-specific rates of reported laboratory-confirmed infectious syphilis cases, 2010-2015, Canada

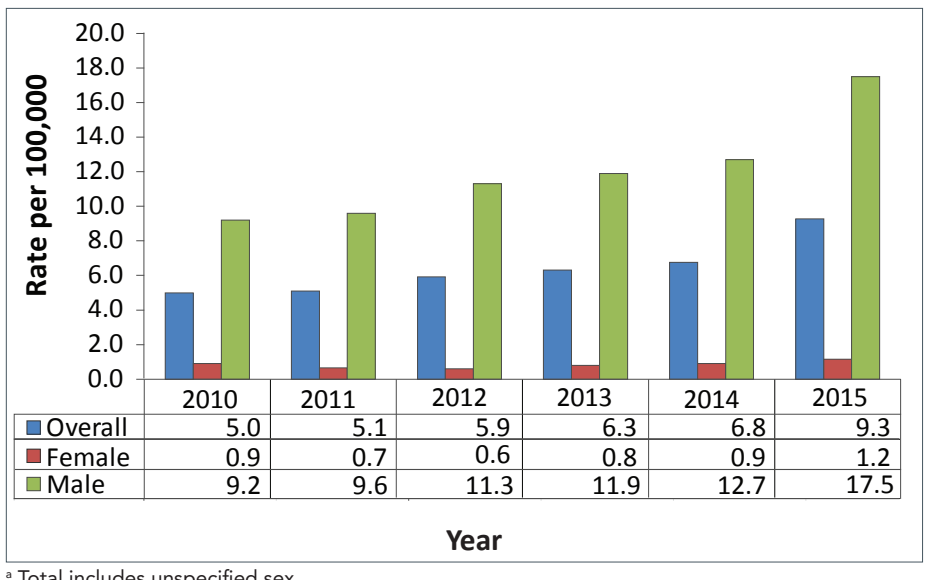

From 2010 to 2015, all age cohorts had a rate increase (data not shown). The highest rates in 2015 (Figure 2) and highest rate increases from 2010 to 2015 were in those aged 25-29 years (a 133\% increase from 2010 to 21.2 cases per 100,000 in 2015) and $30-39$ years (a $109 \%$ increase from 2010 to 18.2 cases per 100,000 in 2015). For those two age groups, the increases were particularly pronounced between 2014 and 2015, accounting for more than half of the increase over 2010-2015. The increase in rate was also high during this period among those aged 60 years and above (a 91.7\% increase, from 1.2 to 2.3 cases per 100,000 ). These three age cohorts (25-29, 30-39 and 60+) had the highest increase of all cohorts among both males and females.

Figure 2: Rates of reported laboratory-confirmed infectious syphilis by sex and age group, 2015, Canada

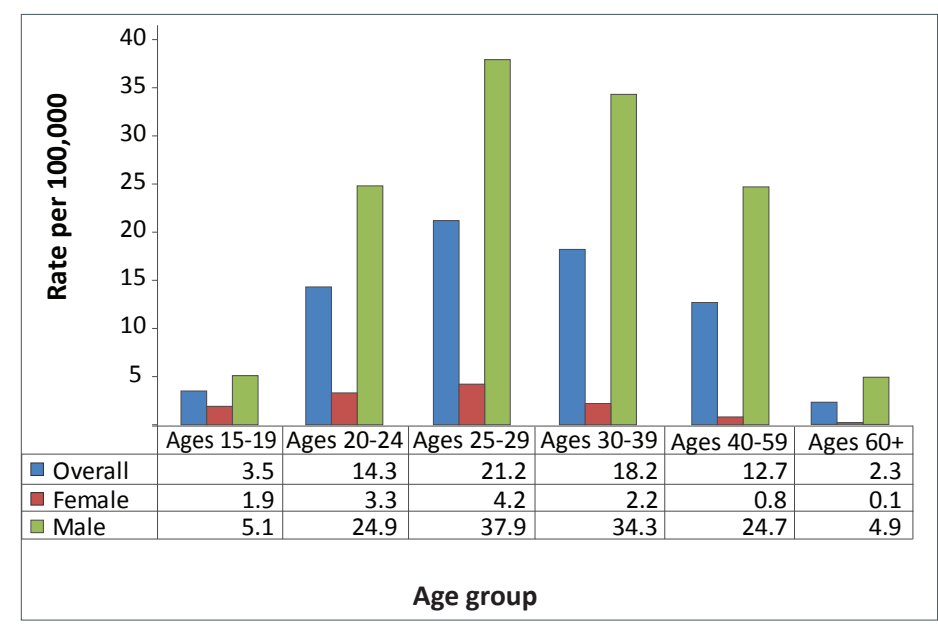

\section{Geographic distribution}

The three provinces with the highest reported rates of laboratory-confirmed syphilis in 2015 were Nunavut, British Columbia and Manitoba (Table 1). The greatest rate decreases were seen in the Northwest Territories, Saskatchewan and New Brunswick. 
Table 1: Number and rate of reported laboratoryconfirmed cases of infectious syphilis, by province and territory in Canada, 2010-2015

\begin{tabular}{|l|r|r|r|r|r|r|}
\hline \multirow{2}{*}{$\begin{array}{c}\text { Province or } \\
\text { territory }\end{array}$} & \multicolumn{7}{|c|}{$\begin{array}{c}\text { Laboratory-confirmed cases by year of } \\
\text { diagnosis (rate per 100,000) }\end{array}$} \\
\cline { 2 - 8 } & 2010 & 2011 & 2012 & 2013 & 2014 & 2015 \\
\hline Alberta & 173 & 94 & 129 & 124 & 157 & 369 \\
& $(4.6)$ & $(2.5)$ & $(3.3)$ & $(3.1)$ & $(3.8)$ & $(8.8)$ \\
\hline British & 92 & 128 & 266 & 454 & 432 & 607 \\
Columbia & $(2.1)$ & $(2.8)$ & $(5.9)$ & $(9.9)$ & $(9.3)$ & $(13.0)$ \\
\hline Manitoba & 17 & 16 & 25 & 59 & 118 & 205 \\
& $(1.4)$ & $(1.3)$ & $(2.0)$ & $(4.7)$ & $(9.2)$ & $(15.8)$ \\
\hline New & 34 & 50 & 21 & 34 & 27 & 31 \\
Brunswick & $(4.5)$ & $(6.6)$ & $(2.8)$ & $(4.5)$ & $(3.6)$ & $(4.1)$ \\
\hline Newfoundland & 4 & 5 & 9 & 8 & 24 & 34 \\
and Labrador & $(0.8)$ & $(1.0)$ & $(1.7)$ & $(1.5)$ & $(4.5)$ & $(6.4)$ \\
\hline Northwest & 3 & 0 & 2 & 0 & 0 & 1 \\
Territories & $(6.9)$ & $(0.0)$ & $(4.6)$ & $(0.0)$ & $(0.0)$ & $(2.3)$ \\
\hline Nova Scotia & 18 & 36 & 63 & 83 & 64 & 43 \\
& $(1.9)$ & $(3.8)$ & $(6.7)$ & $(8.8)$ & $(6.8)$ & $(4.6)$ \\
\hline Nunavut & 0 & 0 & 29 & 57 & 82 & 56 \\
& $(0.0)$ & $(0.0)$ & $(83.6)$ & $(161.0)$ & $(227.6)$ & $(153.3)$ \\
\hline Ontario & 774 & 770 & 835 & 744 & 879 & 1,052 \\
& $(5.9)$ & $(5.8)$ & $(6.2)$ & $(5.5)$ & $(6.4)$ & $(7.6)$ \\
\hline Prince Edward & 0 & 0 & 0 & 5 & 9 & 9 \\
Island & $(0.0)$ & $(0.0)$ & $(0.0)$ & $(3.4)$ & $(6.2)$ & $(6.1)$ \\
\hline Quebec & 546 & 630 & 673 & 631 & 584 & 737 \\
& $(6.9)$ & $(7.9)$ & $(8.3)$ & $(7.7)$ & $(7.1)$ & $(8.9)$ \\
\hline Saskatchewan & 36 & 23 & 6 & 17 & 28 & 24 \\
& $(3.4)$ & $(2.2)$ & $(0.6)$ & $(1.5)$ & $(2.5)$ & $(2.1)$ \\
\hline Yukon & 0 & 0 & 1 & 2 & 0 & 0 \\
& $(0.0)$ & $(0.0)$ & $(2.8)$ & $(5.5)$ & $(0.0)$ & $(0.0)$ \\
\hline Canada & 1,697 & 1,752 & 2,059 & 2,218 & 2,404 & 3,321 \\
& $(5.0)$ & $(5.1)$ & $(5.9)$ & $(6.3)$ & $(6.8)$ & $(9.3)$ \\
\hline
\end{tabular}

\section{Congenital syphilis}

The number of laboratory-confirmed cases of congenital syphilis reported in Canada varied from one to six cases per year in 2010-2015 (Table 2).

Table 2: Number of reported laboratory-confirmed cases and rates of congenital syphilis, 2010-2015, Canada

\begin{tabular}{|l|r|r|r|r|r|r|}
\hline \multirow{2}{*}{ Indicator } & \multicolumn{7}{|c|}{ Year of diagnosis } \\
\cline { 2 - 7 } & $\mathbf{2 0 1 0}$ & $\mathbf{2 0 1 1}$ & $\mathbf{2 0 1 2}$ & $\mathbf{2 0 1 3}$ & $\mathbf{2 0 1 4}$ & $\mathbf{2 0 1 5}$ \\
\hline $\begin{array}{l}\text { Number of } \\
\text { cases }\end{array}$ & 6 & 5 & 3 & 2 & 1 & 6 \\
\hline $\begin{array}{l}\text { Rate per } \\
\begin{array}{l}100,000 \text { live } \\
\text { births }\end{array}\end{array}$ & 1.59 & 1.32 & 0.79 & 0.53 & 0.26 & 1.54 \\
\hline
\end{tabular}

\section{Discussion}

In Canada, the rates of reported cases of infectious syphilis markedly increased from 2010 to 2015 . The burden of syphilis seems to be disproportionately placed on men. Other high-income countries such as the United States of America (USA), Australia and the United Kingdom have reported similar increases in numbers of cases and rates (6-8).

The very high number of cases among males is thought to be mainly because of an increase in cases among MSM (1). Newfoundland and Labrador and Manitoba are among the provinces with the highest increases over 2010-2015. These provinces have reported that increased diagnoses among MSM was the main factor driving rates upwards $(9,10)$. This is of concern as syphilis contraction increases the probability of acquiring and transmitting HIV (1). A greater increase of reported syphilis cases has been observed among MSM living with HIV than among noninfected MSM in both Western Europe and the USA (11).

The causes of the increase in the rate of syphilis among MSM are multifactorial and complex. Changing community norms and behaviours as well as new preventive interventions such as pre-exposure prophylaxis (PrEP) might explain this rise. Many MSM have adopted behaviour patterns such as serosorting (choosing to have condomless sex with partners with the same HIV status) or having condomless oral sex, with the intention of decreasing HIV transmission $(12,13)$. However, the lowered condom use might increase the risk of contracting other STIs $(13,14)$. In a Toronto-based study, condomless anal sex with casual partners in the previous six months was associated with syphilis infection among MSM living with HIV (15). Also of concern is the fact that Internet-based social media are increasingly being used to easily find sex partners. This may promote concurrent partnerships and rates of acquisition of new partners and decrease intervals between sex partners (16). The social mixing patterns with the use of saunas, and the consumption of recreational drugs that may impair judgment in making decisions about sexual acts are also risk factors for acquisition and transmission of syphilis and other STIs $(16,17)$. Lastly, increased risk-taking behaviours and a rise in STI incidence have been reported among HIV-negative MSM using PrEP (18-20). In Canada, PrEP was not significantly used in 2010-2015. However, data from other countries and from research studies highlight the importance of frequent STI screening of MSM on PrEP to ensure that symptomatic and asymptomatic STIs are treated in a timely way to halt transmission, as PrEP use increases over time (21).

This finding highlights the importance of public health action to mitigate transmission of syphilis and identify new risk groups, such as MSM on PrEP.

The rate increase in women is also worrying as congenital syphilis tends to increase with rates of primary and secondary syphilis among women of childbearing age. A recent study on the epidemiology of syphilis in Winnipeg reported that one quarter 
of women with syphilis were pregnant at diagnosis (22). No cases of congenital syphilis were found in the study.

This finding highlights the importance of universal screening of pregnant women in a context of syphilis resurgence in Canada, as recommended by the Canadian Guidelines on Sexually Transmitted Infections (1).

\section{Strengths and limitations}

This surveillance report presents a national portrait of the current infectious syphilis epidemiology and was based on data from all provinces and territories. It describes sex, age and province/ territory-specific rates over a six-year period.

Some limitations of the data should be noted. First, some numbers of cases of infectious and congenital syphilis were low. This leads to less stable rates, especially for congenital syphilis for which less than 10 cases were reported annually in Canada in 2010-2015. Therefore, variations in rates over time should be interpreted with caution. Second, these figures likely underestimate the incidence rate of syphilis from 2010 to 2015 as some infections may be asymptomatic, unscreened, undiagnosed or unreported. Screening, laboratory testing and reporting practices are heterogeneous across provinces and territories, and reports to the PHAC of syphilis cases by stage vary between provinces/territories. Therefore, we were not able to calculate valid stage-specific rates or to report on the number of cases of specific conditions such as neurosyphilis. Likewise, although age structures may vary across provinces and territories, we did not perform standardization by age. Therefore, direct comparison between provinces should be made with caution.

Trend analysis on the data was not performed, which is a limitation of this report. Lastly, risk factors and clinical presentation are not available in this surveillance system, preventing identifying risk factors associated with the observed increased rates.

\section{Conclusion}

In conclusion, syphilis rates in Canada have risen markedly over time. Males make up the vast majority of syphilis cases, and based on data from Canada, USA, Australia and other countries, MSM are one of the groups at highest risk. A better understanding of transmission dynamics and social and sexual networking is needed to guide prevention efforts.

\section{Authors' statement}

YC - Conceptualization, methodology, writing - original draft JM - Software, data collection and curation, validation, formal analysis, visualization, writing - review and editing JS - Writing - original draft, visualization $\mathrm{AL}$ - Validation, formal analysis, visualization, writing - review and editing

JA - Conceptualization, writing - original draft

\section{Conflict of interest}

None.

\section{Contributors}

Chris Archibald: Supervision, writing - review and editing, resources, project administration Jennifer Siushansian: writing - review and editing

\section{Acknowledgements}

It would not have been possible to publish this report without the continuous and greatly appreciated contribution of all provinces and territories.

\section{Funding}

This work was supported by the Public Health Agency of Canada.

\section{References}

1. Expert Working Group for the Canadian Guidelines on Sexually Transmitted Infections. Syphilis. In: Wong T, Latham-Carmanico C, editors. Canadian Guidelines on Sexually Transmitted Infections, 2010. Ottawa (ON): Public Health Agency of Canada; 2010. https://www.canada.ca/ en/public-health/services/infectious-diseases/sexual-healt h-sexually-transmitted-infections/canadian-guidelines/ sexually-transmitted-infections/canadian-guideline s-sexually-transmitted-infections-27.html

2. Eickhoff CA, Decker CF. Syphilis. Dis Mon 2016 Aug;62(8):280-6. DOI (http://dx.doi.org/10.1016/j. disamonth.2016.03.012). PubMed (https://www.ncbi.nlm. nih.gov/entrez/query.fcgi?cmd=Retrieve \&db=PubMed\&li st_uids=27091635\&dopt=Abstract).

3. Finelli L, Berman SM, Koumans EH, Levine WC. Congenital syphilis. Bull World Health Organ 1998;76 Suppl 2:126-8. PubMed (https://www.ncbi.nlm.nih.gov/ entrez/query.fcgi?cmd=Retrieve \&db=PubMed\&list_ uids $=10063689 \&$ dopt $=$ Abstract).

4. Public Health Agency of Canada. Canadian Notifiable Disease Surveillance System national report: 2005-2008. Ottawa (ON): PHAC; 2012. http://publications.gc.ca/ collections/collection_2012/aspc-phac/HP40-75-2012-eng. pdf

5. Public Health Agency of Canada. Case definitions for communicable diseases under national surveillance; results of provincial/territorial $(\mathrm{P} / \mathrm{T})$ consultation process. Can Commun Dis Rep. 2009;35(S2):S1-123. https://www.canada.ca/en/public-health/services/ reports-publications/canada-communicable-disease-reportccdr/monthly-issue/2009-35/definitions-communicabl e-diseases-national-surveillance.html

6. Centers for Disease Control and Prevention. Sexually transmitted disease surveillance 2015. Atlanta (GA): US 
Department of Health and Human Services; 2016. https:// www.cdc.gov/std/stats15/STD-Surveillance-2015-print.pdf

7. The Kirby Institute. HIV, viral hepatitis and sexually transmissible infections in Australia: annual surveillance report 2016. Sydney (AU): University of New South Wales; 2016. https://kirby.unsw.edu.au/sites/default/files/kirby/ report/SERP_Annual-Surveillance-Report-2016_UPD170627. pdf

8. Public Health England. Table 2: New diagnoses \& rates by gender, sexual risk \& age group, 2012-2016. London (UK): Public Health England. https://www.gov.uk/government/ uploads/system/uploads/attachment_data/file/626361/2016_ Table_2_Selected_STI_diagnoses__rates_by_gender__ sexual_risk__age_group.pdf

9. Manitoba Health. Update on infectious syphilis in Manitoba. 2015 Dec. Winnipeg (MB): Manitoba Health. http://www.gov. $\mathrm{mb} . \mathrm{ca} /$ health/publichealth/factsheets/syph_update.pdf

10. Health and Community Services. Syphilis clinical management, 2015. St John's (NL): Government of Newfoundland and Labrador; 2015 Jul 10. http://www. health.gov.nl.ca/health/publichealth/cdc/Syphilis_Clinical_ Mgnt.pdf

11. Abara WE, Hess KL, Neblett Fanfair R, Bernstein KT, Paz-Bailey G. Syphilis trends among men who have sex with men in the United States and Western Europe: a systematic review of trend studies published between 2004 and 2015. PLoS One 2016 Jul;11(7):e0159309. DOI (http://dx.doi. org/10.1371/journal.pone.0159309). PubMed (https://www. ncbi.nlm.nih.gov/entrez/query.fcgi? $\mathrm{cmd}=$ Retrieve\&db=PubM ed\&list_uids=27447943\&dopt=Abstract).

12. Cassels S, Katz DA. Seroadaptation among men who have sex with men: emerging research themes. Curr HIV/AIDS Rep 2013 Dec;10(4):305-13. DOI (http://dx.doi.org/10.1007/ s11904-013-0188-2). PubMed (https://www.ncbi.nlm.nih. gov/entrez/query.fcgi?cmd=Retrieve\&db=PubMed\&lis t_uids $=24234489 \&$ dopt=Abstract).

13. Marcus U, Schmidt AJ, Hamouda O. HIV serosorting among HIV-positive men who have sex with men is associated with increased self-reported incidence of bacterial sexually transmissible infections. Sex Health 2011 Jun;8(2):184-93. DOI (http://dx.doi.org/10.1071/SH10053). PubMed (https:// www.ncbi.nlm.nih.gov/entrez/query.fcgi?cmd=Retrieve\&db= PubMed\&list_uids=21592432\&dopt=Abstract).

14. Truong HM, Kellogg T, Klausner JD, Katz MH, Dilley J, Knapper $\mathrm{K}$ et al. Increases in sexually transmitted infections and sexual risk behaviour without a concurrent increase in HIV incidence among men who have sex with men in San Francisco: a suggestion of HIV serosorting? Sex Transm Infect 2006 Dec;82(6):461-6. DOI (http://dx.doi.org/10.1136/ sti.2006.019950). PubMed (https://www.ncbi.nlm.nih. gov/entrez/query.fcgi? cmd=Retrieve\&db=PubMed\&lis t_uids $=17151031 \& d o p t=A b s t r a c t)$.

15. Remis RS, Liu J, Loutfy MR, Tharao W, Rebbapragada A, Huibner $S$ et al. Prevalence of sexually transmitted viral and bacterial infections in HIV-positive and HIV-negative men who have sex with men in Toronto. PLoS One 2016
Jul;11(7):e0158090. DOI (http://dx.doi.org/10.1371/ journal.pone.0158090). PubMed (https://www.ncbi.nlm. nih.gov/entrez/query.fcgi?cmd=Retrieve\&db=PubMed\&li st_uids $=27391265 \&$ dopt $=$ Abstract $)$.

16. Fenton KA, Breban R, Vardavas R, Okano JT, Martin T, Aral $S$ et al. Infectious syphilis in high-income settings in the 21 st century. Lancet Infect Dis 2008 Apr;8(4):244-53. DOI (http:// dx.doi.org/10.1016/S1473-3099(08)70065-3). PubMed (https://www.ncbi.nlm.nih.gov/entrez/query.fcgi?cmd=Retrie ve\&db=PubMed\&list_uids=18353265\&dopt=Abstract).

17. Grov C, Breslow AS, Newcomb ME, Rosenberger JG, Bauermeister JA. Gay and bisexual men's use of the Internet: research from the 1990s through 2013. J Sex Res 2014;51(4):390-409. DOI (http://dx.doi.org/10.1080/002 24499.2013.871626). PubMed (https://www.ncbi.nlm.nih. gov/entrez/query.fcgi?cmd=Retrieve\&db=PubMed\&lis t_uids=24754360\&dopt=Abstract).

18. Lal L, Audsley J, Murphy DA, Fairley CK, Stoove M, Roth $\mathrm{N}$ et al.; VicPrEP Study Team. Medication adherence, condom use and sexually transmitted infections in Australian preexposure prophylaxis users. AIDS 2017 Jul;31(12):1709-14. DOI (http://dx.doi.org/10.1097/ QAD.0000000000001519) PubMed (https://www.ncbi.nlm. nih.gov/entrez/query.fcgi?cmd=Retrieve\&db=PubMed\&li st_uids $=28700394 \&$ dopt=Abstract).

19. Kojima N, Davey DJ, Klausner JD. Pre-exposure prophylaxis for HIV infection and new sexually transmitted infections among men who have sex with men. AIDS 2016 Sep;30(14):2251-2. DOI (http://dx.doi.org/10.1097/ QAD.0000000000001185). PubMed (https://www.ncbi.nlm. nih.gov/entrez/query.fcgi?cmd=Retrieve\&db=PubMed\&li st_uids=27314179\&dopt=Abstract).

20. Scott HM, Klausner JD. Sexually transmitted infections and pre-exposure prophylaxis: challenges and opportunities among men who have sex with men in the US. AIDS Res Ther 2016 Jan;13:5. DOI (http://dx.doi.org/10.1186/ s12981-016-0089-8). PubMed (https://www.ncbi.nlm.nih. gov/entrez/query.fcgi?cmd=Retrieve\&db=PubMed\&lis t_uids=26793265\&dopt=Abstract).

21. Jenness SM, Weiss KM, Goodreau SM, Gift T, Chesson H, Hoover KW et al. Incidence of Gonorrhea and Chlamydia Following Human Immunodeficiency Virus Preexposure Prophylaxis Among Men Who Have Sex With Men: A Modeling Study. Clin Infect Dis 2017;65(5):712-8. DOI (http://dx.doi.org/10.1093/cid/cix439). PubMed (https:// www.ncbi.nlm.nih.gov/entrez/query.fcgi?cmd=Retrieve\&db= PubMed\&list_uids=28505240\&dopt=Abstract).

22. Shaw SY, Ross C, Nowicki DL, Marshall S, Stephen S, Davies $C$ et al. Infectious syphilis in women: what's old is new again? Int J STD AIDS 2017 Jan;28(1):77-87. DOI (http://dx.doi. org/10.1177/0956462415627397). PubMed (https://www. ncbi.nlm.nih.gov/entrez/query.fcgi?cmd=Retrieve\&db=PubM ed\&list_uids=26769755\&dopt=Abstract). 


\section{Appendix: Case definitions of confirmed cases of infectious and congenital syphilis ${ }^{\mathrm{a}}$}

Laboratory confirmation of early congenital syphilis infection (within two years of birth):

- Identification of Treponema pallidum by dark-field microscopy, fluorescent antibody or equivalent examination of material from nasal discharges, skin lesions, placenta, umbilical cord or autopsy material of a neonate (up to four weeks of age) OR

- Reactive serology (non-treponemal and treponemal) from venous blood (not cord blood) in an infant/child with clinical, laboratory or radiographic evidence of congenital syphilis whose mother is without documented evidence of adequate treatment

OR

- Detection of T. pallidum DNA in an appropriate clinical specimen

Laboratory confirmation of primary syphilis infection:

- Identification of T. pallidum by dark-field microscopy, fluorescent antibody, nucleic acid testing or equivalent examination of material from a chancre or a regional lymph node

OR

- Presence of one or more typical lesions (chancres) and reactive treponemal serology, regardless of non-treponemal test reactivity, in individuals with no previous history of syphilis

OR

- Presence of one or more typical lesions (chancres) and a fourfold or greater increase in the titre over the last known non-treponemal test in individuals with a past history of syphilis treatment

Laboratory evidence of infection for secondary syphilis:

- Identification of T. pallidum by dark-field microscopy, fluorescent antibody, nucleic acid testing or equivalent examination of mucocutaneous lesions, condylomata lata and reactive serology (non-treponemal and treponemal)

OR

- Presence of typical signs or symptoms of secondary syphilis (e.g. mucocutaneous lesions, alopecia, loss of eyelashes and lateral third of eyebrows, iritis, generalized lymphadenopathy, fever, malaise or splenomegaly) AND either a reactive serology (non-treponemal and treponemal) OR a fourfold or greater increase in titre over the previous known non-treponemal test

Laboratory confirmation of early latent syphilis infection ( $<1$ year after infection):

An asymptomatic patient with reactive serology (treponemal and/or non-treponemal) who, within the previous 12 months, had one of the following:

- nonreactive serology

- symptoms suggestive of primary or secondary syphilis

- exposure to a sexual partner with primary, secondary or early latent syphilis

a Quebec's definition requires the use of two tests including a treponemal one for a diagnostic of primary, secondary or early latent syphilis 